\title{
A Central Composite Design Approach to Minimize HAZ of TIG Weldments
}

\author{
Andrew Ozigagun and Raphael Biu
}

\begin{abstract}
Welding is a multi-input multi-output fabrication process, which requires a multi-response optimization technique. In this present work, the effect of heat affected zone and percentage dilution on the quality of Tungsten Inert Gas welded joints was investigated using mild steel plates. The Central Composite Design matrix was adopted to perform the welding experiment and collect the data, thereafter Response Surface Methodology (RSM) models was employed to minimize heat affected zone and percentage dilution with very significant statistical results. The result shows that the quadratic model was the most suitable for the HAZ data and the percentage dilution data with a $P$-value $<0.05$ and $R^{2}$ value of $88 \%$ and $90 \%$ for the $\mathrm{HAZ}$ and percentage dilution respectively.
\end{abstract}

Index Terms-Heat Affected Zone, Percentage Dilution, Central Composite Design, Tungsten Inert Gas, Welding.

\section{INTRODUCTION}

A weld joint consist of a weld metal and heat affected zone (HAZ), the weld metal is the fusion zone where dilution of the deposited metal wire occurs by melting of the base metal. Hence the properties of the weld metal are dependent on several interacting factors such as filler material, degree of dilution, base metal and welding process. In contrast the heat affected zone composition is the same as that of the base metal, and is usually defined as the volume of base metal affected by the weld thermal cycle. Mechanical properties of a welded joint are dictated mainly by weld bead contour, HAZ area, precipitation process and heat input during welding [4]. Base metal in the vicinity of deposited weld metal undergoes a considerable change metallurgically and mechanically due to weld thermal cycle. Size of this heat affected zone (HAZ) depends on the heat input and is to be predicted for better analysis and understanding of the characteristics of HAZ affecting the microstructure and properties of the welded steel [3]. Reference [1] Classified weld metal into four main areas such as CGHAZ, fine grained supercritical HAZ (FGHAZ), intercritical HAZ (ICHAZ) and subcritical HAZ (SCHAZ). Among these, CGHAZ is the most affected area during welding process due to rapid cooling which caused hardening which in turn can be the main factor of cleavage cracking. Reference [5] has investigated the effects of coarse initial grain size on the microstructure, hardness and HAZ of low carbon steel. Reference [2] stated that weld quality is strongly influenced by various input process parameters which makes welding a multi-input multi-output process.

Published on September 23, 2019

Authors are with the Department of Production Engineering, Faculty of Engineering, University of Benin, P.M.B 1154, Benin City, Edo State, Nigeria. (e-mail: andrewzigs@yahoo.com, raphaelbiu@gmail.com)
The improvement of weld quality has been the common interest of most welding researchers today, a weld is said to be good when the strength of the weldment is more than that of the parent materials, this can be achieved by optimizing the input parameters during the welding process. It is clear from the literature survey that a lot of work has been done in past years regarding the modelling of bead geometry with respect to TIG parameters. Various statistical and modelling techniques have used by different authors. HAZ, which is a critical zone in any weldment, has been only modelled by [3]. They correlated the HAZ area with the heat input and other welding parameters and comparison was done between HAZ produced in bead on plate welds and pipe joint welds. No studies in the past, however, been carried out to find the interactive effect of TIG welding parameters on the size of heat affected zone and percentage dilution of mild steel weld The improper combination of this parameters affects the weld bead geometry, and can result in residual stresses and microstructural defects. Research shows that various statistical and prediction techniques have been developed to define the relationship between the input parameters and output variables. There are varieties of Artificial Intelligence (AI) methods available which includes time series models, regression models, adaptive neuro-fuzzy inference systems (ANFIS), artificial neural network (ANN) etc. have been implemented as major techniques for controlling and monitoring the welding processes. Presently the use of ANN has increased gradually in the field of engineering. As described by [6], it is one of the powerful modeling techniques based on statistical approach, presently practiced in the field of engineering for modeling complex relationships which are difficult to explain with physical models. Reference [7] and [8] interpreted that the Response surface methodology (RSM) is one of the most efficient statistical optimization technique for both single and multiresponse optimizations. In the present work, an attempt is made to fill this gap by modelling the relationship between current voltage and gas flow rate and percentage dilution and heat affected zone by using Response Surface Methodology and Artificial Neural Network models. Reference [9] introduced ANN modelling as an alternative technique to those currently in the literature to predict the hardness of HAZ, and hence, trying to control it to minimize the risk of hydrogen assisted cold cracking in welding inservice pipelines by the hot tapping technique. The model developed included materials characteristics; chemical composition and hardness (as inputs), the peak temperature, holding time and cooling rate of the HAZ thermal cycle simulation were also used as key inputs in the model to predict the HAZ hardness. It was reported that the hardness of HAZ increases with increasing the following: carbon 
content, original hardness of pipe or fitting material and more rapid cooling. They compared the predictive capabilities of the models developed with other published works to the neural network model they developed. It was clear that the neural networks model produced a much lower error across a broader range of HAZ hardness values.

\section{ReSEARCH Methodology}

\section{A. Design of Experiment}

The experimental design considers the following factors such as welding current, gas flow rate, welding speed and voltage as input. The experimental matrix was generated with the design expert software; the central composite design was the most suitable for this experiment. This process followed the rules of repetition, randomization and local control so as to achieve an optimal experimental design. The input factors considered and their levels is shown in the table below.

TABLE I: PROCESS FACTORS AND THEIR RANGE

\begin{tabular}{lllll}
\hline \hline \multirow{2}{*}{ Parameters } & \multirow{2}{*}{ Unit } & \multirow{2}{*}{ Symbol } & Coded value & Coded value \\
\cline { 5 - 5 } & & & Low $(-1)$ & High $(+1)$ \\
\hline Current & Amp & A & 180 & 240 \\
Gas flow rate & Lit/min & F & 16 & 22 \\
Voltage & Volt & V & 18 & 24 \\
Welding speed & $\mathrm{cm} / \mathrm{min}$ & $\mathrm{S}$ & 3 & 4.5 \\
\hline \hline
\end{tabular}

TABLE II: EXPERIMENTAL RESULTS OF HAZ

\begin{tabular}{llll}
\multicolumn{4}{c}{ TABLE II: EXPERIMENTAL RESULTS OF HAZ } \\
\hline \hline Current & voltage & Gas flow & HAZ \\
\hline 170.00 & 16.64 & 17.00 & 1.3 \\
\hline 150.00 & 22.00 & 15.00 & 1.3 \\
\hline 170.00 & 20.00 & 17.00 & 2.1 \\
\hline 170.00 & 20.00 & 17.00 & 2.18 \\
\hline 170.00 & 20.00 & 20.36 & 2.3 \\
\hline 203.64 & 20.00 & 17.00 & 1.4 \\
\hline 136.36 & 20.00 & 17.00 & 1.9 \\
\hline 150.00 & 18.00 & 15.00 & 2 \\
\hline 190.00 & 22.00 & 19.00 & 1.5 \\
\hline 170.00 & 23.36 & 17.00 & 1.2 \\
\hline 170.00 & 20.00 & 17.00 & 2 \\
\hline 170.00 & 20.00 & 13.64 & 2.2 \\
\hline 190.00 & 22.00 & 15.00 & 1.39 \\
\hline 190.00 & 18.00 & 15.00 & 1.6 \\
\hline 170.00 & 20.00 & 17.00 & 2.2 \\
\hline 170.00 & 20.00 & 17.00 & 2.4 \\
\hline 150.00 & 22.00 & 19.00 & 2 \\
\hline 150.00 & 18.00 & 19.00 & 1.4 \\
\hline 190.00 & 18.00 & 19.00 & 1.7 \\
\hline 170.00 & 20.00 & 17.00 & \\
\hline \hline
\end{tabular}

\section{B. Experimental Procedure}

Power Hacksaw was used for cutting the mild steel plate to size measuring $60 \times 40 \times 10 \mathrm{~mm}$. The grinding machine was used for preparing the groove on the double transverse side of the plates of Mild Steel Subsequently single 'V' groove angles (30 degree) were cut in the plates with $2 \mathrm{~mm}$ root faces for a total of 60 degree inclined angle between After the V-groove preparation, the Mild Steel were ready for the welding. The mild steel plates were tightly clamped during welding. The root gap of $2 \mathrm{~mm}$ is provided between the two plates while performed for the welding. The Vgroove butt welding is performed during TIG welding process. The tungsten non consumable electrode having diameter $3 \mathrm{~mm}$ was used in experiment. The argon gas is used as a shielding gas. The pressure regulator was used to adjust the gas flow rate during operation. The filler metal ER309L having $2 \mathrm{~mm}$ diameter was used for the welding. The direct current Electrode positive (reverse polarity) was used for the welding.

\section{Materials used for the Experiment}

Mild Steel is one of the most common of all metals and one of the least expensive steels used. It is found in almost every product created from metal. It is easily weldable, very durable. Having less than $2 \%$ carbon, it will magnetize well and being relatively inexpensive can be used in most projects requiring a lot of steel.

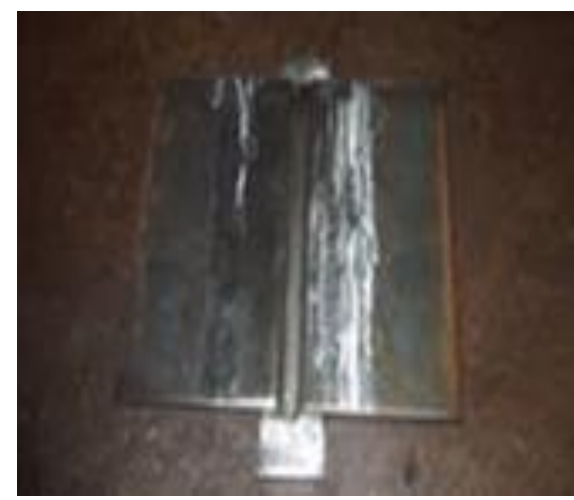

Fig. 1. Welded Sample

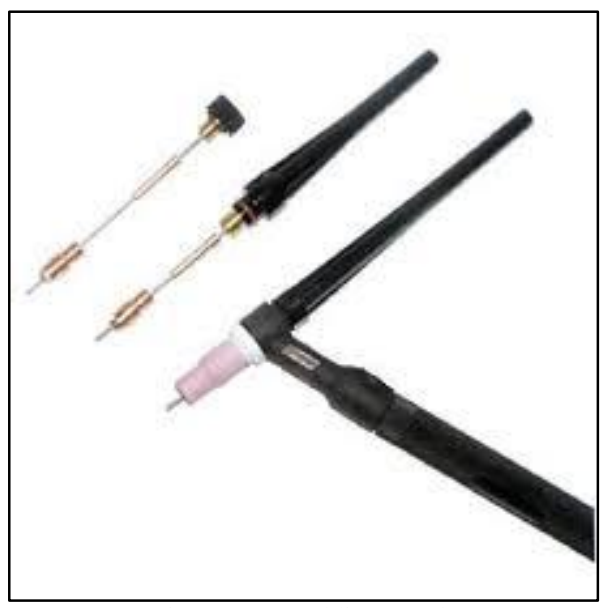

Fig. 2. TIG Welding Torch

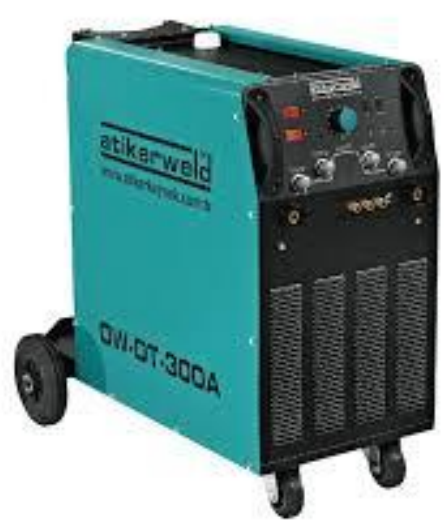

Fig. 3. TIG Welding Machine 


\section{RESULTS AND DISCUSSION}

The results for HAZ was analyzed by using ANOVA in order to identify the significant factors affecting the performance measures. It is clear from results so obtained in Table III that current is the most important parameter having the most significant effect on the HAZ and then voltage and gas flow rate have almost negligible effect on the same.in assessing the strength of the quadratic model towards minimizing the heat affected zone one-way analysis of variance (ANOVA) table was generated which is presented in Table III.

TABLE III: ANOVA TABLE FOR HAZ

\begin{tabular}{lllllll}
\hline \hline & Sum of & & Mean & F & p-value & \\
\hline Source & Squares & Df & Square & Value & Prob > F & \\
\hline Model & 2.49 & 9 & 0.28 & 8.44 & 0.0013 & Significant \\
\hline $\begin{array}{l}\text { A- } \\
\text { CURRENT }\end{array}$ & 0.37 & 1 & 0.37 & 11.30 & 0.0072 & \\
\hline $\begin{array}{l}\text { B- } \\
\text { VOLTAGE }\end{array}$ & 0.070 & 1 & 0.070 & 2.13 & 0.1748 & \\
\hline $\begin{array}{l}\text { C-GAS } \\
\begin{array}{l}\text { FLOW } \\
\text { RATE }\end{array}\end{array}$ & 0.044 & 1 & 0.044 & 1.35 & 0.2722 & \\
\hline AB & 0.044 & 1 & 0.044 & 1.32 & 0.2765 & \\
\hline \hline
\end{tabular}

\begin{tabular}{lllllll}
\hline \hline $\mathrm{AC}$ & 0.078 & 1 & 0.078 & 2.38 & 0.1543 & \\
\hline $\mathrm{BC}$ & 0.13 & 1 & 0.13 & 3.88 & 0.0771 & \\
\hline $\mathrm{A}^{\wedge} 2$ & 0.40 & 1 & 0.40 & 12.29 & 0.0057 & \\
\hline $\mathrm{B}^{\wedge} 2$ & 1.37 & 1 & 1.37 & 41.85 & $<0.0001$ & \\
\hline $\mathrm{C}^{\wedge} 2$ & 0.029 & 1 & 0.029 & 0.88 & 0.3707 & \\
\hline Residual & 0.33 & 10 & 0.033 & & & \\
\hline Lack of Fit & 0.052 & 5 & 0.010 & 0.19 & 0.9545 & $\begin{array}{l}\text { not } \\
\text { significant }\end{array}$ \\
\hline \hline
\end{tabular}

To validate the adequacy of the quadratic model based on its ability to minimize the heat affected zone the goodness of fit statistics presented in Table IV.

TABLE IV: GOODNESS OF FIT STATISTICS FOR HAZ

\begin{tabular}{llll}
\hline \hline Std. Dev. & 0.18 & R-Squared & 0.8836 \\
\hline Mean & 1.80 & Adj R-Squared & 0.7789 \\
\hline C.V. \% & 10.05 & Pred R-Squared & 0.7084 \\
\hline PRESS & 0.82 & Adeq Precision & 9.492 \\
\hline
\end{tabular}

To diagnose the statistical properties of the response surface model, the normal probability plot of residual for minimizing heat affected zone is produced and presented in Fig. 4.

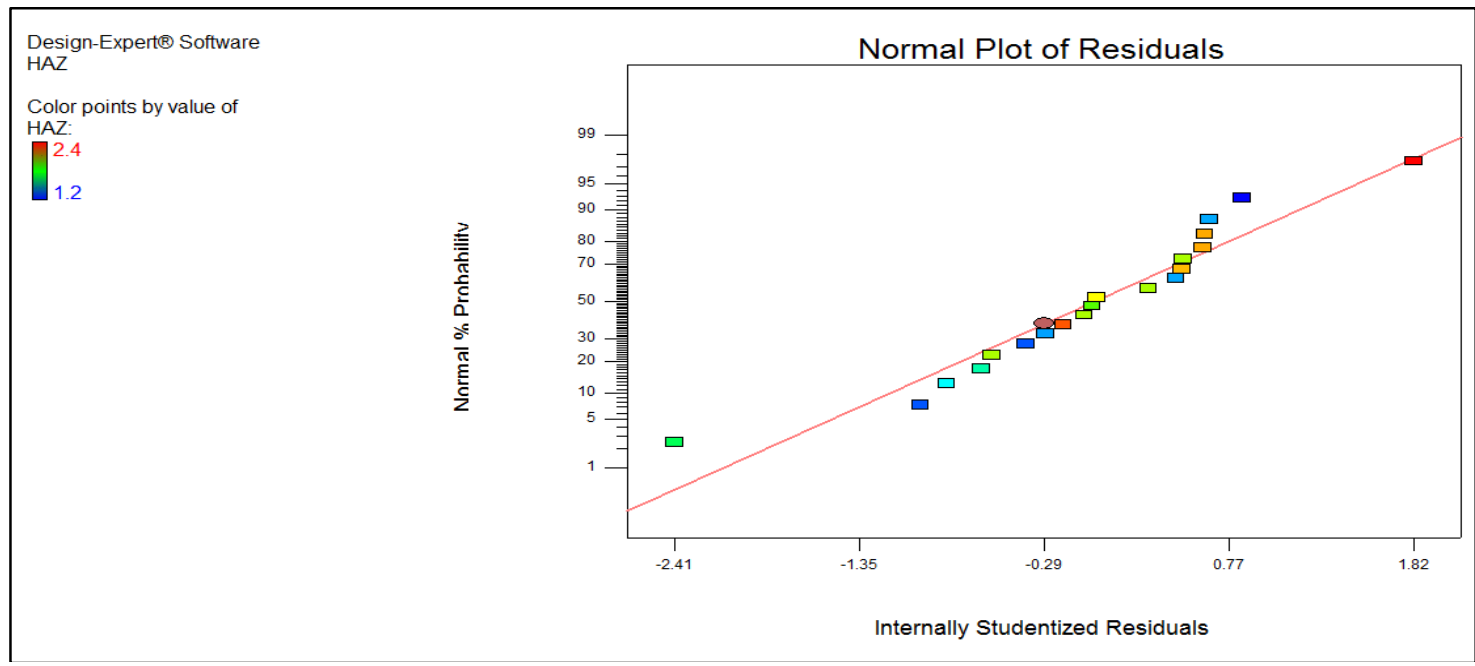

Fig. 4. Normal probability plot of studentized residuals for minimizing heat affected zone

To study the combined interaction between the heat affected zone ,current and voltage a surface plot is produced as shown in Fig. 5

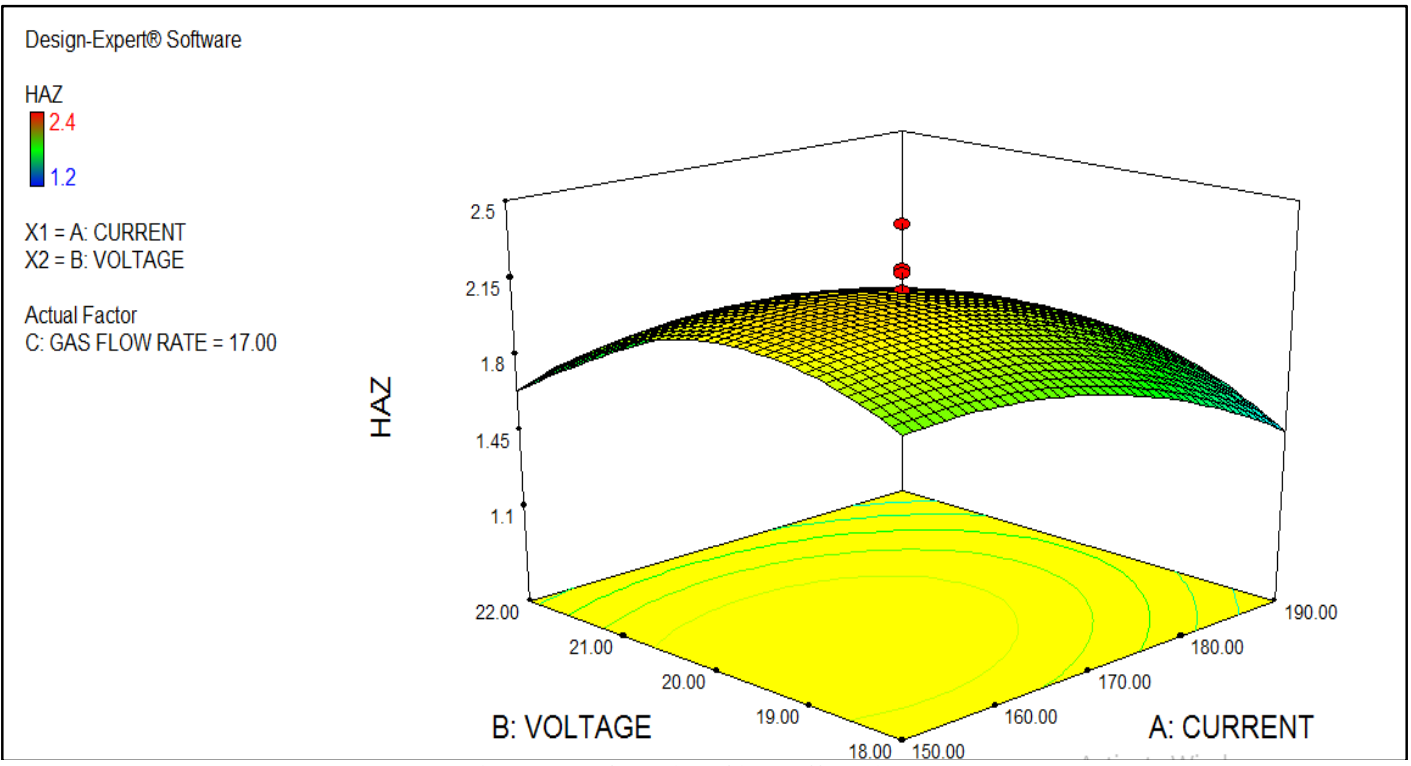

Fig. 5. A surface plot of heat affected zone 
TABLE V: THE NUMERICAL OPTIMAL SOLUTION

\begin{tabular}{|c|c|c|c|c|c|c|}
\hline $\begin{array}{l}\text { Numb } \\
\text { er }\end{array}$ & $\begin{array}{l}\text { CURRE } \\
\text { NT }\end{array}$ & $\begin{array}{l}\text { VOLTA } \\
\text { GE }\end{array}$ & $\begin{array}{l}\text { GAS } \\
\text { FLO } \\
\text { W } \\
\text { RAT } \\
\text { E }\end{array}$ & HAZ & $\begin{array}{l}\text { Desir } \\
\text { ability }\end{array}$ & \\
\hline 1 & 150.00 & 22.00 & 15.00 & 1.40413 & 0.911 & $\begin{array}{l}\text { Select } \\
\text { ed }\end{array}$ \\
\hline 2 & 150.01 & 22.00 & 15.03 & 1.40687 & 0.907 & \\
\hline 3 & 150.00 & 21.98 & 15.00 & 1.4138 & 0.906 & \\
\hline 4 & 150.00 & 22.00 & 15.07 & 1.4111 & 0.900 & \\
\hline 5 & 151.39 & 22.00 & 15.00 & 1.42723 & 0.896 & \\
\hline 6 & 151.75 & 22.00 & 15.00 & 1.43286 & 0.893 & \\
\hline 7 & 150.00 & 22.00 & 15.13 & 1.41705 & 0.892 & \\
\hline 8 & 150.00 & 22.00 & 15.15 & 1.4186 & 0.890 & \\
\hline 9 & 152.26 & 22.00 & 15.00 & 1.44075 & 0.888 & \\
\hline 10 & 150.00 & 22.00 & 15.18 & 1.42169 & 0.885 & \\
\hline 11 & 150.00 & 22.00 & 15.19 & 1.42318 & 0.883 & \\
\hline 12 & 150.91 & 21.88 & 15.00 & 1.47279 & 0.876 & \\
\hline 13 & 150.00 & 22.00 & 15.26 & 1.42986 & 0.874 & \\
\hline 14 & 153.94 & 22.00 & 15.00 & 1.46505 & 0.871 & \\
\hline 15 & 150.00 & 21.78 & 15.00 & 1.49617 & 0.866 & \\
\hline 16 & 150.00 & 22.00 & 15.35 & 1.43966 & 0.860 & \\
\hline 17 & 150.00 & 21.73 & 15.02 & 1.51886 & 0.852 & \\
\hline 18 & 150.00 & 22.00 & 15.44 & 1.44874 & 0.848 & \\
\hline 19 & 157.85 & 22.00 & 15.00 & 1.51272 & 0.834 & \\
\hline 20 & 158.04 & 22.00 & 15.00 & 1.51475 & 0.832 & \\
\hline 21 & 150.00 & 22.00 & 15.59 & 1.46434 & 0.827 & \\
\hline 22 & 159.52 & 22.00 & 15.00 & 1.52918 & 0.819 & \\
\hline 23 & 150.00 & 21.48 & 15.00 & 1.61405 & 0.805 & \\
\hline 24 & 150.00 & 22.00 & 15.80 & 1.48828 & 0.797 & \\
\hline 25 & 162.92 & 22.00 & 15.00 & 1.55551 & 0.789 & \\
\hline
\end{tabular}

\section{CONCLUSION}

1. The optimization of HAZ in tungsten inert gas welding of mild steel was done using ANOVA. The minimum value of HAZ is $1.331 \mathrm{~mm}$ at current value 190A.

2 . The current is the most important parameter having the most significant effect on the HAZ.

3. On increasing the current, the value of HAZ which is not desirable.

In this paper the influence of TIG welding parameters on heat affected zone has been examined on the quality of weldments, this study has systematically applied the response surface methodology (RSM) to prioritize the HAZ of Tungsten inert gas mild steel weld. Result of the study have shown that the RSM are highly effective tools for modelling the interaction between the current, voltage, gas flow rate and the heat affected zone of TIG mild steel weld. It was observed that the HAZ of TIG mild steel weld are strongly influenced by input variables such as current. The surface plot shows that current and voltage were observed to have the highest significant effect on the HAZ of TIG mild steel weld. The result shows that a current of $190 \mathrm{amps}$, voltage of 18 volts, and gas flow rate of $19.00 \mathrm{~L} / \mathrm{min}$ will result in a welding process with Heat affected zone $1.331 \mathrm{~mm}$. This solution was selected by design expert as the optimal solution with a desirability value of $94.3 \%$.

\section{REFERENCES}

[1] M Sarizam. (2012) "Variant analysis of bainite phase transformation in heat affected zone (HAZ) of Cr-Mo steel". Master dissertation. Osaka University, Japan.

[2] K.Y. Benyounis, A.G. Olabi, M.S.J. Hashmi (2005) "Residual Stresses Prediction for $\mathrm{Co}_{2}$ Laser Butt-Welding of 304-Stainless Steel". Applied Mechanics and Materials, Vols. 3-4. Trans Tech Publications. 2005. P. 125-30.

[3] V. Gunaraj and N. Murugan, (1999) "Prediction and Comparison of the Area of the Heat-Affected Zone for The Bead-On Plates and Bead-On-Joint in Submerged Arc Welding of Pipes", Journals of Materials Processing Tech., Vol. 95, Pp. 246-261.

[4] Lancaster, J.F. (1999). Metallurgy of welding (6th ed.). Abington, Cambridge: Abington Pub. ISBN 1-85573-428-1

[5] M. Eroglu, M. Aksoy and N. Orhan (1999). "Effect of coarse initial grain size on microstructure and mechanical properties of weld metal and HAZ of a low carbon steel". Materials Science and Engineering A. 269(1): 59-66.

[6] G.B. Rajkumar and N. Murugan, (2012) Prediction of Weld Bead Geometry Using Artificial Neural Networks on 2205 Duplex Stainless Steel. European Journal of Scientific Research, Issn 1450-216x (78) $85-92$.

[7] A. Aggarwal, H. Singh, P. Kumar and M. Singh (2008) Optimizing Power Consumption for CNC Turned Parts Using Response Surface Methodology and Taguchi's Technique A, Comparative Analysis. Journal of Materials Processing Technology, (2008), 373-384.

[8] I. Asilturk and S. Neseli (2012) Multi Response Optimization of CNC Turning Parameters Via Taguchi Method-Based Response Surface Analysis. Measurement, (45), 785-794.

[9] Z. Sterjovski, D. Nolan, D. Dunne and J. Norrish, (2004)" Predicting The HAZ Hardness of Pipeline and Tap Fitting Steels with Artificial Neural Networks" In Proceedings of The 4th Inter. Conf. On Pipeline Technology, University of Wollongong, New, Australia, 2004, Pp. 1233-1245. 